\title{
Operational properties of a photovoltaic system with three single phase inverters
}

\author{
S. Seme, G. Štumberger and J. Voršič \\ University of Maribor \\ Faculty of Electrical Engineering and Computer Science \\ Smetanova 17, 2000 Maribor (Slovenia) \\ Phone: +3862 220 7179, Fax number: +3862 252 5481, e-mail: sebastijan.seme@uni-mb.si
}

\begin{abstract}
In the recent years the number of photovoltaic systems which are connected to the distribution networks is increasing all over the world. It is to expect further increase in the future. This work focuses on analysis of a photovoltaic system with three single-phase inverters connected to the electric grid. Photovoltaic systems often use single-phase inverters. The disadvantage of such systems is asymmetrical unbalanced delivery of electricity to the distribution network. This means that the currents in individual lines are unbalanced which leads to the unbalanced three-phase power generation.
\end{abstract}

\section{Key words}

Single phase inverters, Photovoltaic system, Analysis, Renewable energy,

\section{Introduction}

European union's directive upon increasing the production of electricity from renewable energy till 2020 has contributed to growth of photovoltaic systems connected to electric grid. Most of photovoltaic systems connected to the grid use single-phase inverter. Smaller photovoltaic systems [1-6] use one single-phase inverter. Bigger photovoltaic systems use more single-phase inverters in master slave concept [7] where one of the inverter is superior to the others and it takes care of suitable operation of other inverters in the chain. There are not many photovoltaic systems which use three-phase inverters [8-11]. However the single-phase inverter connected to the three-phase grid could sometimes cavse problems.

In the case study, this work focuses on analysis of a photovoltaic system with three single-phase inverters connected to the electric grid. Three single-phase inverters connected to the grid were tested during the day. Throughout the test, the inverter's input current and input voltage as well as output current and output voltage were measured. They were used to calculate the inverter's input and output power, power factor PF and efficiency $\eta$. The total harmonic distortion THD is determined by applying Fourier analysis of current and voltage. This photovoltaic system is connected to the strong electric grid with low impedance. Consequently, the value of THD is small, as shown in the results presented. The main problem of photovoltaic systems with three single-phase inverters connected to the grid is in the asymmetrical distribution of which causes additional losses related with energy transmission.

\section{Photovoltaic system}

Fig. 1 shows the photovoltaic (PV) system installed at University of Maribor, Faculty of Electrical Engineering and Computer Science. PV system was built as a roof of the car parking.

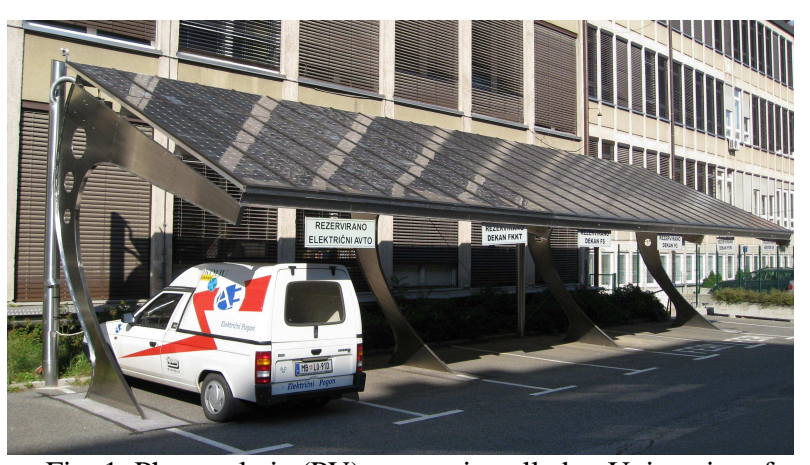

Fig. 1. Photovoltaic (PV) system installed at University of Maribor.

The PV system is structured into three subsystems. Each subsystem uses 24 modules and one single-phase inverter. The total power of the PV system is $7.5 \mathrm{kWp}$. The main components of the PV system block diagram are show in Fig. 2. 


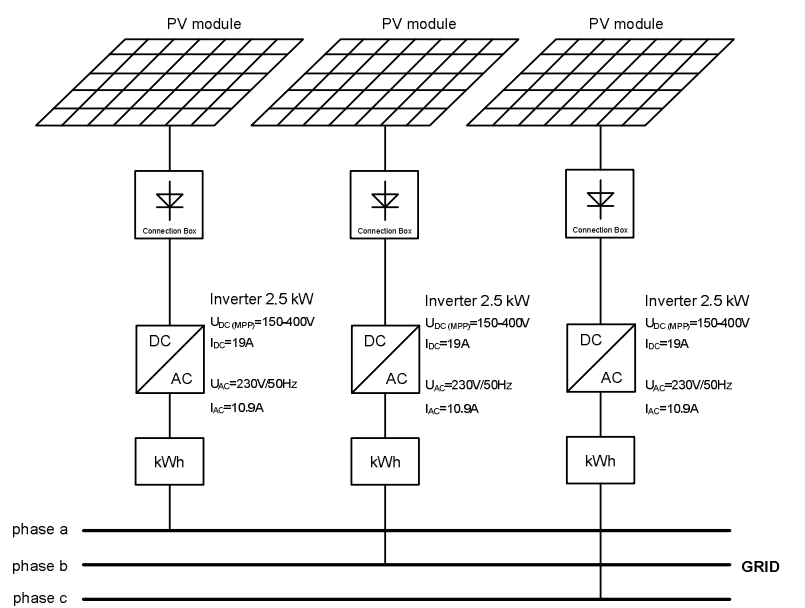

Fig. 2. System block diagram of a photovoltaic system 7,5 kWp installed at University of Maribor.

There are 72 mono-crystal modules of 105 watts which are connected to three sub-arrays (power of each sub array is $2.5 \mathrm{kWp}$ ).

In the case study, experimental set-up consisting of the described PV system connected to the grid (which included PV modules, inverters ...), current and voltage measurement chains and a signal processor board dSpace DS 1103 which is used as a data acquisition system with sampling frequency $10 \mathrm{kHz}$, is applied

\section{Analysis}

On the inverters' input side the DC voltage $u_{\mathrm{DC}}$ and current $i_{\mathrm{DC}}$ were measured while on the output side the AC voltage $u_{\mathrm{AC}}$ and current $i_{\mathrm{AC}}$ were measured. Input voltage and current as well as output voltage and current were sampled with sampling frequency $10 \mathrm{kHz}$ in $1 \mathrm{~s}$ long time window. The RMS values of voltage and current were determined by (1) to (6):

$$
\begin{aligned}
& U_{k D C}=\sqrt{\frac{1}{N} \sum_{j=1}^{N} u_{k D C}^{2}(j)} \\
& I_{k D C}=\sqrt{\frac{1}{N} \sum_{j=1}^{N} i_{k D C}^{2}(j)} \\
& U_{k A C}=\sqrt{\frac{1}{N} \sum_{j=1}^{N} u_{k A C}^{2}(j)} \\
& I_{k A C}=\sqrt{\frac{1}{N} \sum_{j=1}^{N} i_{k A C}^{2}(j)}
\end{aligned}
$$

where $k \in\{$ phase a, phase $\mathrm{b}$, and phase $\mathrm{c}\}, N$ is the number of simples while $j$ denotes the sample.

$$
\begin{aligned}
& U_{A C}^{2}=U_{a A C}^{2}+U_{b A C}^{2}+U_{c A C}^{2} \\
& I_{A C}^{2}=I_{a A C}^{2}+I_{b A C}^{2}+I_{c A C}^{2}
\end{aligned}
$$

The active input and output power were determined by (7) to (10):

$$
\begin{aligned}
& P_{k D C}=\frac{1}{N} \sum_{j=1}^{N} u_{k D C}(j) i_{k D C}(j) \\
& P_{k A C}=\frac{1}{N} \sum_{j=1}^{N} u_{k A C}(j) i_{k A C}(j) \\
& P_{D C}=P_{a \mathrm{DC}}+P_{\mathrm{bDC}}+P_{c \mathrm{DC}} \\
& P_{A C}=P_{a A C}+P_{\mathrm{b} A C}+P_{c A C}
\end{aligned}
$$

where $k \in\{$ phase $\mathrm{a}$, phase $\mathrm{b}$, and phase $\mathrm{c}\}$. When the values of output voltage $U_{k \mathrm{AC}}$ and output current $I_{k \mathrm{AC}}$ and active output power $P_{k \mathrm{AC}}$ are obtained, the power factor $P F_{k}$, for each phase separately and total power factor $P F$ can be calculated by (11) and (12):

$$
\begin{aligned}
& P F_{k}=\frac{P_{k A C}}{U_{k A C} I_{k A C}} \quad k \in\{\mathrm{a}, \mathrm{b} \text { in } \mathrm{c}\} \\
& P F=\frac{P_{A C}}{U_{A C} I_{A C}}
\end{aligned}
$$

The efficiency is calculated by (13):

$$
\eta=\frac{P_{A C}}{P_{D C}}
$$

The RMS values of individual harmonic components were determined by Fourier analysis. They were used to determine $T H D$ for inverters' output voltages and currents. The output voltage $T H D_{U}$ and the output current $T H D$ were determined by (14) and (15):

$$
\begin{aligned}
& T H D_{U k A C}=\sqrt{\frac{\sum_{h=2}^{40} U_{k h A C}^{2}}{U_{k 1 A C}^{2}}} \quad k \in\{\mathrm{a}, \mathrm{b} \text { in } \mathrm{c}\} \\
& T H D_{I k A C}=\sqrt{\frac{\sum_{h=2}^{40} I_{k h A C}^{2}}{I_{k 1 A C}^{2}}} \quad k \in\{\mathrm{a}, \mathrm{b} \text { in } \mathrm{c}\}
\end{aligned}
$$

\section{Results}

Results measured during the tests performed on three grid-connected inverters are presented in Figs. 3 to 7. In Figs. 3 to 5 results are given as functions of output power $P_{\text {AC. }}$. Fig. 3 shows RMS values of all inverters' input DC current $I_{\mathrm{DC}}$ and voltage $U_{\mathrm{DC}}$ together with the input power $P_{\mathrm{DC}}$. Fig. 4 shows RMS values of output AC current $I_{\mathrm{AC}}$ and voltage $U_{\mathrm{AC}}$. 

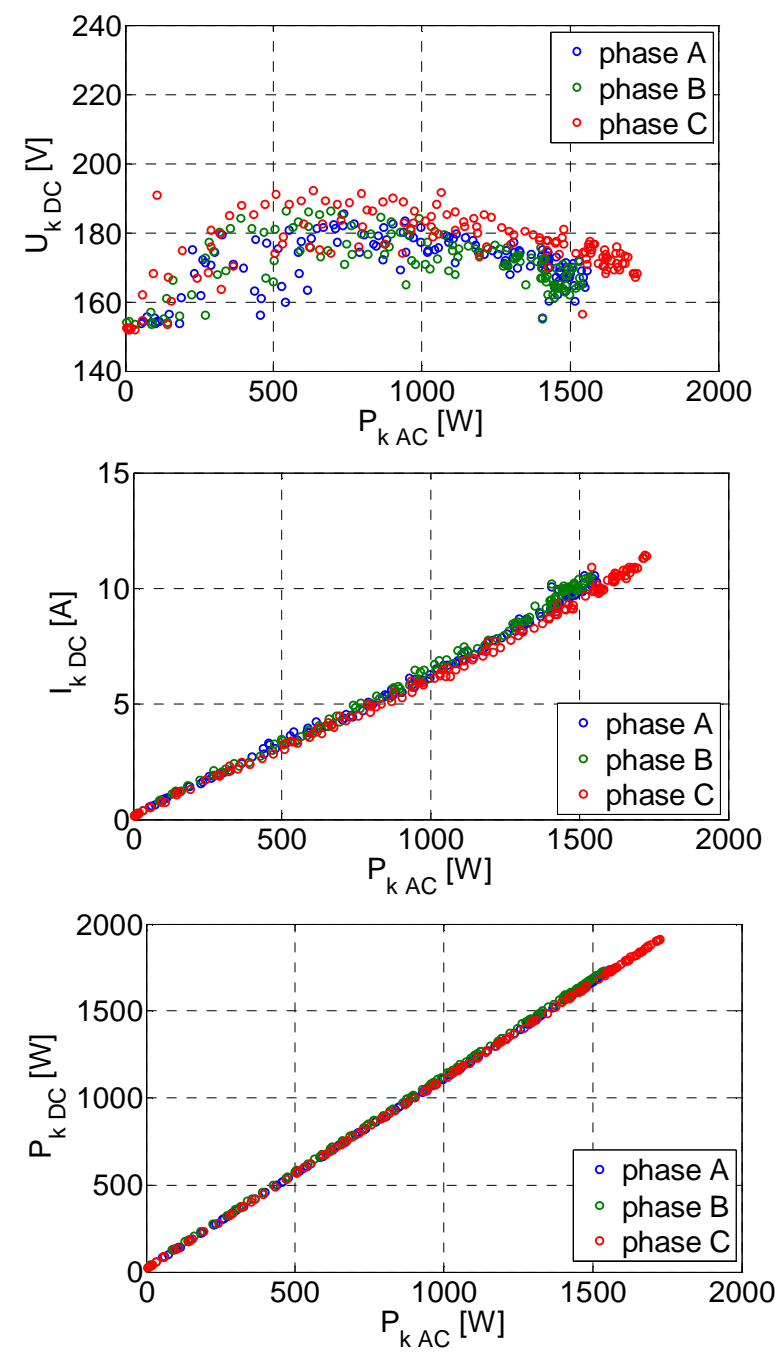

Fig. 3. RMS value of input voltage $U_{\mathrm{DC}}$, RMS value of input current $I_{\mathrm{DC}}$ and input power $P_{\mathrm{DC}}$ measured during tests, given as functions of output power $P_{\mathrm{AC}}$.
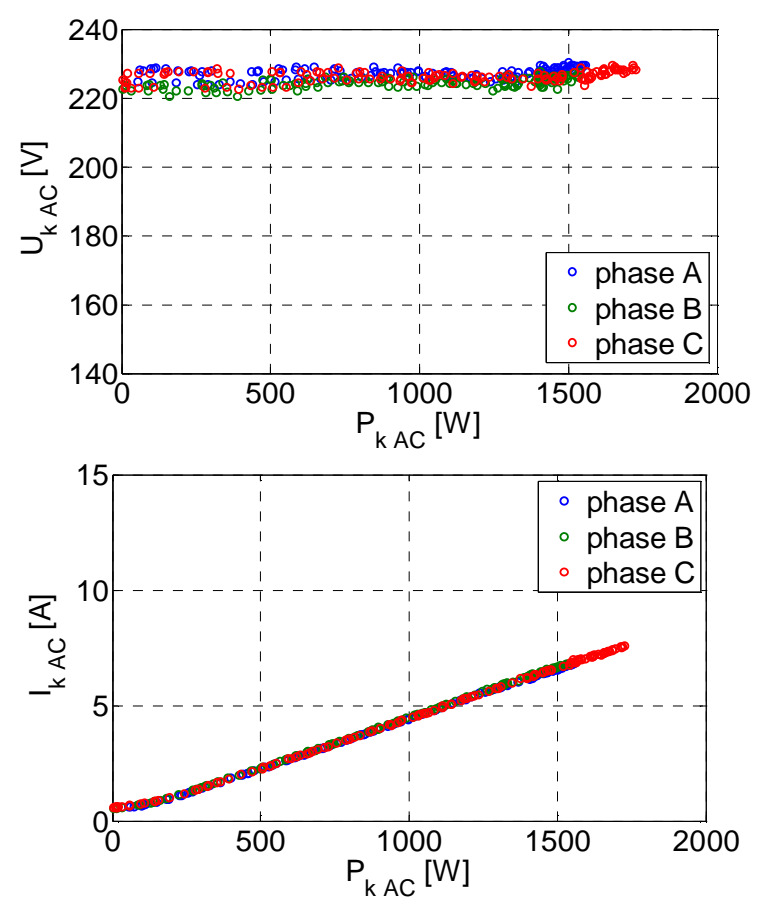

Fig. 4. RMS value of outpu voltage $U_{\mathrm{AC}}$ and RMS value of output current $I_{\mathrm{AC}}$ measured during tests, given as functions of output power $P_{\mathrm{AC}}$.
Fig. 5 shows power factor $P F$ given as a function of output power $P_{\mathrm{AC}}$, while efficiency $\eta$ is shown in Fig. 6 .
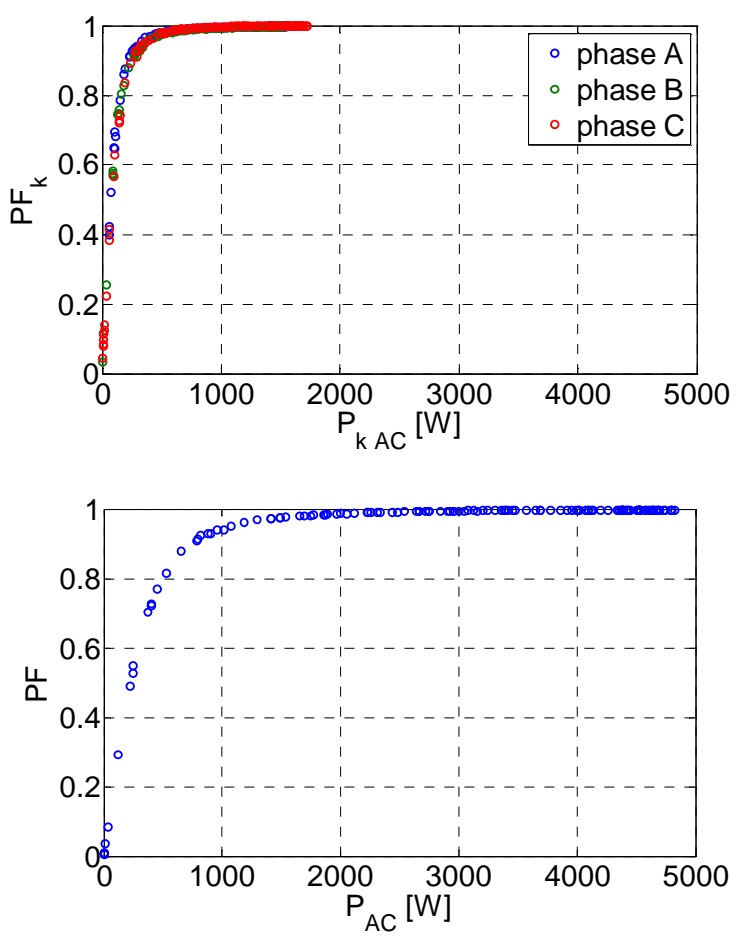

Fig.5. Power factor $P F$ measured during tests, given as functions of output power $P_{\mathrm{AC}}$.

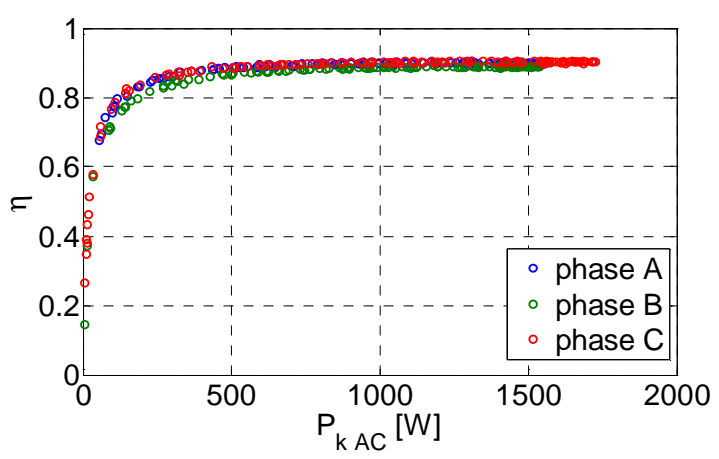

Fig.6. Efficiency $\eta$ measured during test, , given as functions of output power $P_{\mathrm{AC}}$.

Fig. 7 shows active input $P_{\mathrm{DC}}$ and output $P_{\mathrm{AC}}$ of all inverters, given as functions of time $t$. 

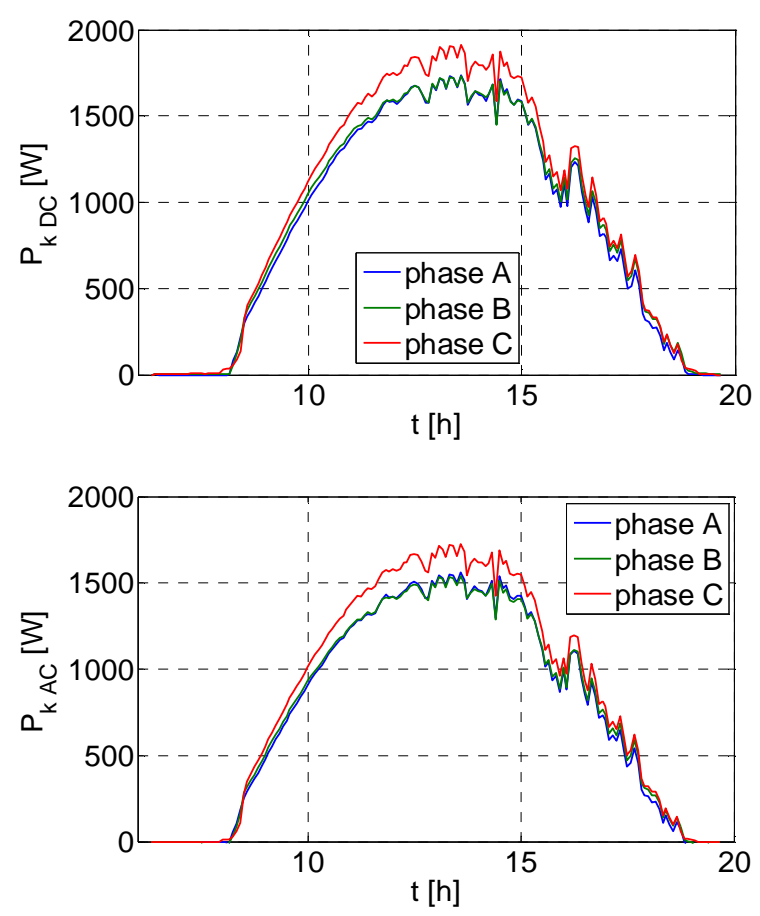

Fig. 7. Input $P_{\mathrm{DC}}$ and output $P_{\mathrm{AC}}$ power, given as functions of time $t$.

Fig. 7 shows the main problem of using three singlephase inverters. Differences among phases show clearly that the sub-array which is connected on phase $\mathrm{C}$ produces more energy. In this case the system is asymmetrical.

Fig. 8 shows voltage and current THD marked as $\mathrm{THD}_{\mathrm{U}}$ and $\mathrm{THD}_{\mathrm{I}}$.
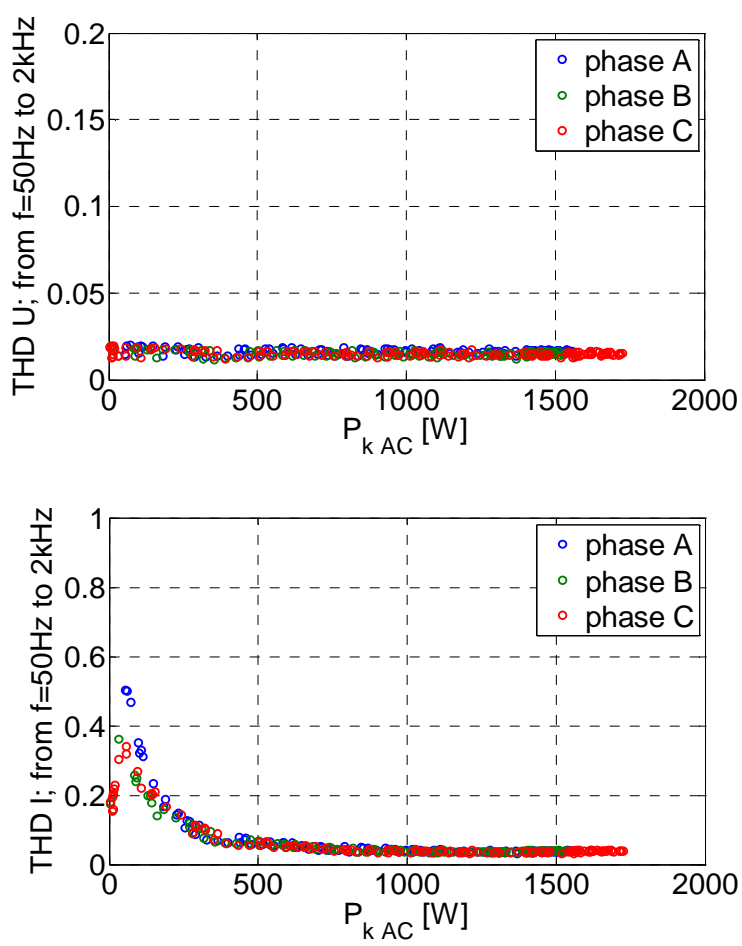

Fig. 8. Voltage and current THD, given as functions of output power $P_{\mathrm{AC}}$.

\section{Conclusion}

Analysis of single-phase inverters for photovoltaic system is performed in the paper. It is shown that the main problem of photovoltaic systems with three singlephase inverters connected to the grid is in the asymmetrical distribution of power. The results clearly show that the sub-array which is connected to the phase $\mathrm{C}$ produces more energy.

\section{References}

[1] Khaehintung N., Sirisuk P., Kunakorn A.: Gridconnected Photovoltaic System with Maximum Power Point Tracking using Self-Organizing Fuzzy Logic Controller, Power Electronics and Drives Systems, 2005.

[2] Jan S., Agarwal V.: A Single-Stage Grid Connected Inverter Topology for Solar PV System With Maximum Power Point Tracking, IEEE Transactions on Power Elctronics, 22, 1928-1940, 2007.

[3] Boonmee C., Plangklang B., Watjanatepin N.: System performance of a three-phase PV-grid-connected system installed in Thailand: Data monitored analysis, Renewable energy 34, 384-389, 2009.

[4] Štumberger G., Seme S., Deželak K., Hanžič A., Voršič J.: Analysis of a single phase inverter for photovoltaic systems operating in a weak electric grid, International Conference on Renewable Energies and Power Quality (ICREPQ), 2008.

[5] http://elektrarna.feri.uni-mb.si/default.aspx

[6] Andrei H., Dogaru-Ulieru V., Chicco G., Cepisca C., Spertino F.: Photovoltaic applications, Journal of Materials Processing Technology, 181, 267-273, 2007.

[7] Maranda W., De Mey G., De Vos A.: Optimization of the master-slave inverter system for grid-connected photovoltaic plants, Energy Conversion and Menagement, 39, 1239-1246, 1998.

[8] Young Chan Shin, Young Roc Kim, Byung Hun Ra, Joon Sun Moon: Development of 200kW Grid-Connected Photovoltaic Inverter, The $7^{\text {th }}$ International Conference on Power Electronics, Korea, 2007.

[9] Mekhilef S., Ahmed M. E., Younis M. A. A.: Performance of Grid Connected Photovoltaic Inverter with Maximum Power Point Tracker and Power Factor Control, International Journal of Power Electronics 1, 4962, 2008.

[10] Alonso-Martinez J., Arnaltes S.: A Three-Phase GridConnected Inverter for Photovoltaic Application Using Fuzzy MPPT, International Conference on Renewable Energies and Power Quality (ICREPQ), 2006

[11] Dejia Z., Zhengming Z., Eltawil M., Liqiang Y.: Design and Control of a Three-Phase Grid-Connected Photovoltaic System with Developed Maximum Power Point Tracking, Applied Power Electronics Conference and Exposition, 2008. 